Miho Klaić

Danko Brezak

Tomislav Staroveški

Zrinka Murat

https://doi.org/10.21278/TOF.43404

ISSN 1333-1124

eISSN 1849-1391

\title{
ON-LINE WORKPIECE HARDNESS MONITORING IN STONE MACHINING
}

\begin{abstract}
Summary
The application of four types of process signals in the indirect on-line monitoring of stone hardness has been analysed in this paper. Cutting forces, servomotor currents, vibration and acoustic emission signals were measured during the drilling of three types of stones characterised by different hardness and heterogeneity values. A group of features were extracted from each signal from the time and frequency domain. Their capacity to correctly classify stone hardness was analysed using an artificial neural network classifier. Stone samples were drilled with new drill bits and drill bits worn to three different wear levels in order to analyse the influence of tool wear on the hardness classification process. Nine combinations of cutting parameters were applied for each drill wear level and stone type. Features extracted from the vibration signals obtained the best results in the stone hardness classification. The results indicate their potential industrial application, since they have achieved a high classification precision regardless of the drill bit wear level.
\end{abstract}

Key words: $\quad$ stone drilling, hardness classification, process monitoring, signal analysis

\section{Introduction}

Although stone is one of the oldest materials, market demands for products made of stone are still continuously rising. Stone is a heterogeneous and anisotropic material characterized by mineral composition, texture and structure. Significant property variations of different types of stones affect the complexity of the machining process. Hardness is one of the most important stone properties with a strong influence on cutting forces. Variations in hardness in the cutting zone often increase wear dynamics of the cutting tool and, consequently, result in the cutting tool and/or workpiece breakage. The determination of hardness and other physico-mechanical parameters of non-homogeneous and anisotropic stone structures is a challenging task and is usually performed in accredited laboratories [1].

Testing of mechanical properties can be performed by direct and indirect methods. Direct methods provide precise information about material properties, but also require a relatively complex preparation of surface samples. Direct methods for measuring stone hardness were suggested in 1978 by the International Society for Rock Mechanics [2]. They 
primarily include methods according to Knoop and Vickers, while Brinell's and Rockwell's methods are not recommended due to stone fragility. Hardness measurements according to Shore and Schmidt are also proposed. However, those measurements provide general information about hardness without specifying its value for each phase of the stone sample.

Several studies have shown a correlation between hardness measured by direct methods and other mechanical properties, such as compressive strength or elasticity [3-5]. They have resulted in the conclusion that stone microstructure (density, grain size and porosity) must also be taken into consideration. The correlation between hardness and atmospheric conditions has also been observed in [6] and explained as a consequence of a chemical reaction.

All those methods are mainly carried out in laboratory conditions and are limited by the size of samples collected in the field or by the method used for sample collection in the case of interventions on historical heritage or cultural monuments [7]. They can give precise information about stone hardness in the case of monolithic, homogeneous types of stones, but are fairly unreliable for heterogeneous stones with complex textures. Furthermore, direct methods cannot be used on-line during the machining process. From the aspects of machining process safety, higher productivity and product quality, as well as potential application of adaptive process control systems, it is necessary to provide a reliable hardness monitoring during the cutting operation. Therefore, an indirect monitoring approach based on the correlation of stone hardness and different process signals measured during the cutting process has been analysed in this study.

Several indirect methods for the estimation of stone mechanical properties in drilling operations have already been proposed. The most frequently utilised process parameters are axial force and feed velocity. Billim [8] and Stavropoulou et al. [9] determined a correlation between stone sample hardness and tool feed velocity in the drilling process at a constant axial force. Valentini et al. [10] and Pamplona et al. [11] found a correlation between compressive strength, axial force and feed velocity. Al-Naddaf et al. [12] compared the impact of stone porosity on an axial force during stone drilling and indicated a great possibility of error when direct methods for measuring stone porosity are used due to the nonhomogeneous structure of stone. Yurdakul and Akdas [13] determined the sample hardness by means of current signals of servomotors drives.

One of the most important influential factors in on-line hardness monitoring during stone machining is tool wear. Tool wear was not analysed in the aforementioned studies, but only in studies concerning rock drilling, such as $[14,15]$. Higher tool wear levels imply higher forces and servomotor currents, which can then be misinterpreted as higher stone hardness. Cutting forces and servomotor currents were two most utilised types of signals for the indirect monitoring of stone mechanical properties or the machining process modelling $[16,17]$. Other types of signals often used in industrial monitoring systems, such as vibration and acoustic emission signals [18-21], were not analysed.

Therefore, the main goal of this experimental study was to analyse a multi-sensor approach to the stone hardness classification during the drilling process as well as the capacity of the selected process signals to correctly classify stone hardness without the information about the tool wear level. Classification features were extracted from four types of signals (cutting forces, servomotor currents, vibration and acoustic emission signals) in the time and frequency domain. Three stone types of different hardnesses, drills belonging to four different wear levels and nine combinations of machining parameters were mutually combined. The details about the experiment, results and discussion are given in the following sections. 


\section{Materials and methods}

\subsection{Stone samples and hardness measurements}

Hardness classification during the stone drilling process was performed using three types of stones whose chemical composition is characterized by different major constituents or their content: S1 (micrite 60\%, sparry calcite 35\%), S2 (dolomite $80.9 \%$, calcite $18.6 \%$ ) and S3 (dolomite 97.8\%, calcite 2.1\%). During the preparation of stone samples, larger pieces of stone were cut into smaller samples $(200 \times 90 \times 30 \mathrm{~mm})$. Due to a relatively high surface roughness, samples were additionally wet polished in several phases (3000 grit polishing pad was used in the last phase).

Most of the commercially available hardness testers are stand-alone instruments, which either lack a camera support or use single camera for indentation measurement. Such vision systems lack lighting and a field of view required for the texture-based measurement area selection. None of the available testers have a second camera with a suitable setup for targeting specific textures, which would be very practical for stone materials. In order to overcome the abovementioned disadvantages, an advanced hardness measurement device was built and mounted on a CNC testbed z-axis instead of the main spindle (Fig. 1).

The device is composed of 3 sections: a texture vision system (I), an indentation feed drive (II) and an indentation measurement vision system (III). The sample measurements began with the selection of an initial starting point using surface texture camera images taken with the texture vision system. The indentation position was marked and the texture image was saved for reference. The indentation feed drive was then moved to a previously marked position using $\mathrm{CNC}$ axes and the intender was pressed on the surface using a $5 \mathrm{~N}$ axial force within a period of $10 \mathrm{~s}$. After that, the indenter drive was retracted and an image of indentation was taken using the indentation measurement vision system. The image was subsequently analysed using the IC Measure software (v.1.2, April 2016). The software gave information about the length of the longest diagonal of the indentation (Fig. 2). This parameter, together with the load applied to the indenter, was necessary for quantifying the hardness value according to the Knoop hardness test (EN 14205:2003).
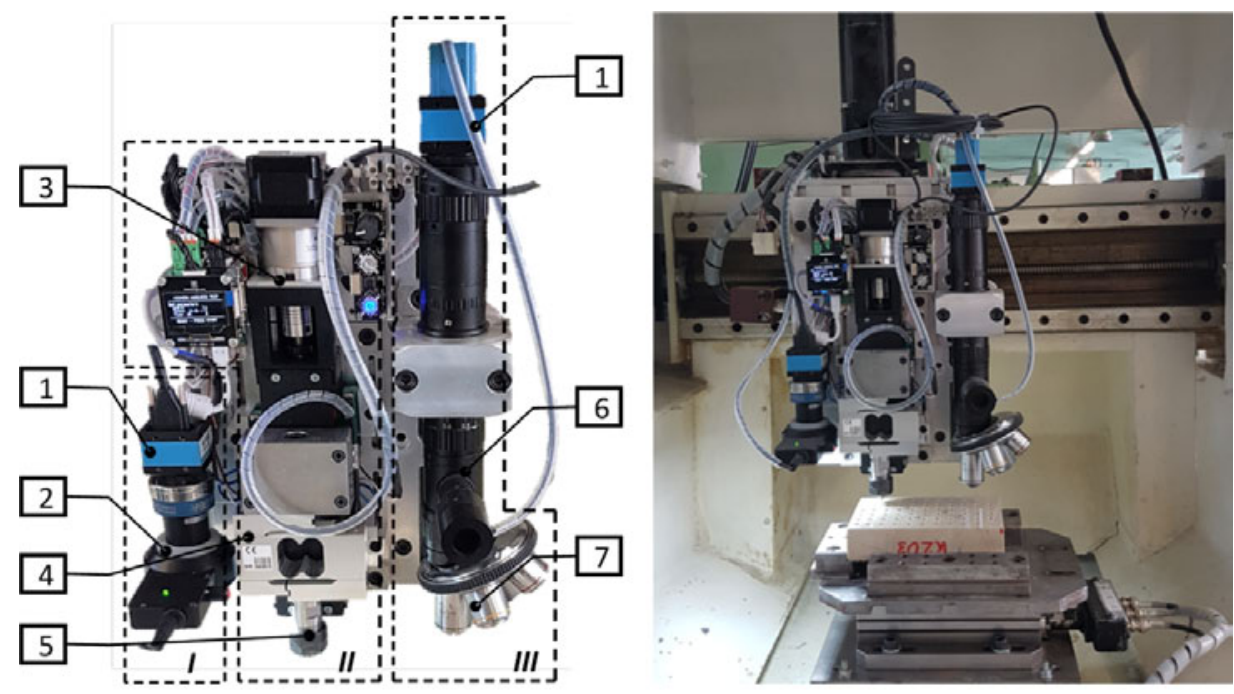

1. Industrial camera

2. Telecentric lenses

3. Linear guide

4. Force sensor
5. Indenter clamping head

6. Lenses with coaxial illumination

7. Rotary head with microscopic lens

Fig. 1 Hardness testing device 

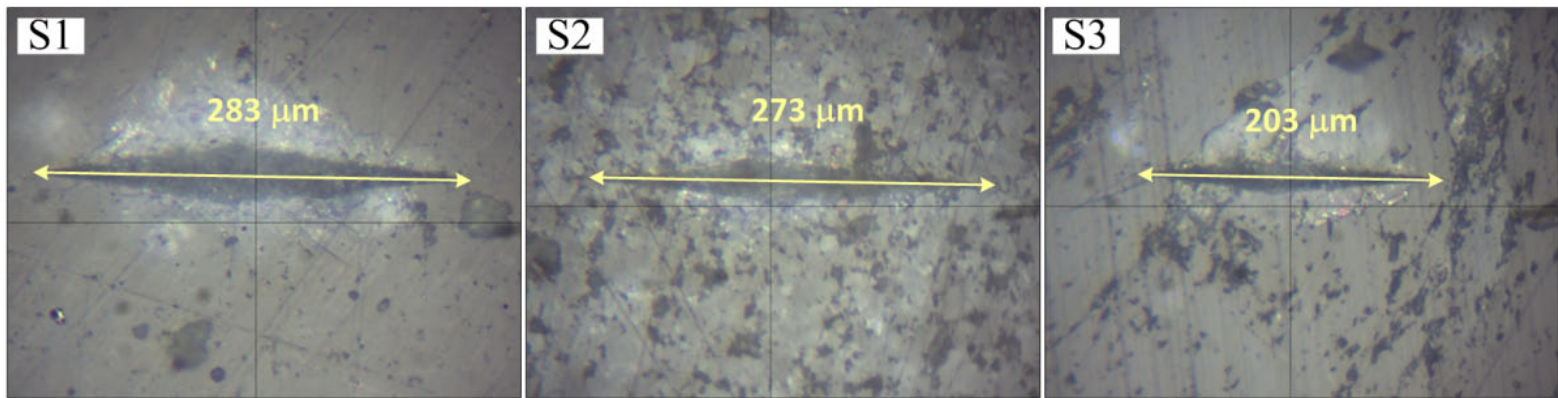

Fig. 2 Images of indents performed by using Knoop hardness test indenter

Considering the non-homogenous sample structure, 1,440 hardness measurements were performed in total on the same CNC machine used for machining all drilling cycles. As a custom-made hardness measuring device was used, samples did not have to be additionally prepared for the measurements, i.e. cut to a smaller size, which is time consuming and sometimes problematic due to the workpiece damages caused by the cutting process. For each type of stone, 480 hardness values were collected (120 measurements performed on each of four samples belonging to every stone type - Fig. 3). The median hardness values for each type of stone were 1651.5 MPa (S1), 1868.7 MPa (S2) and 2661.6 MPa (S3).

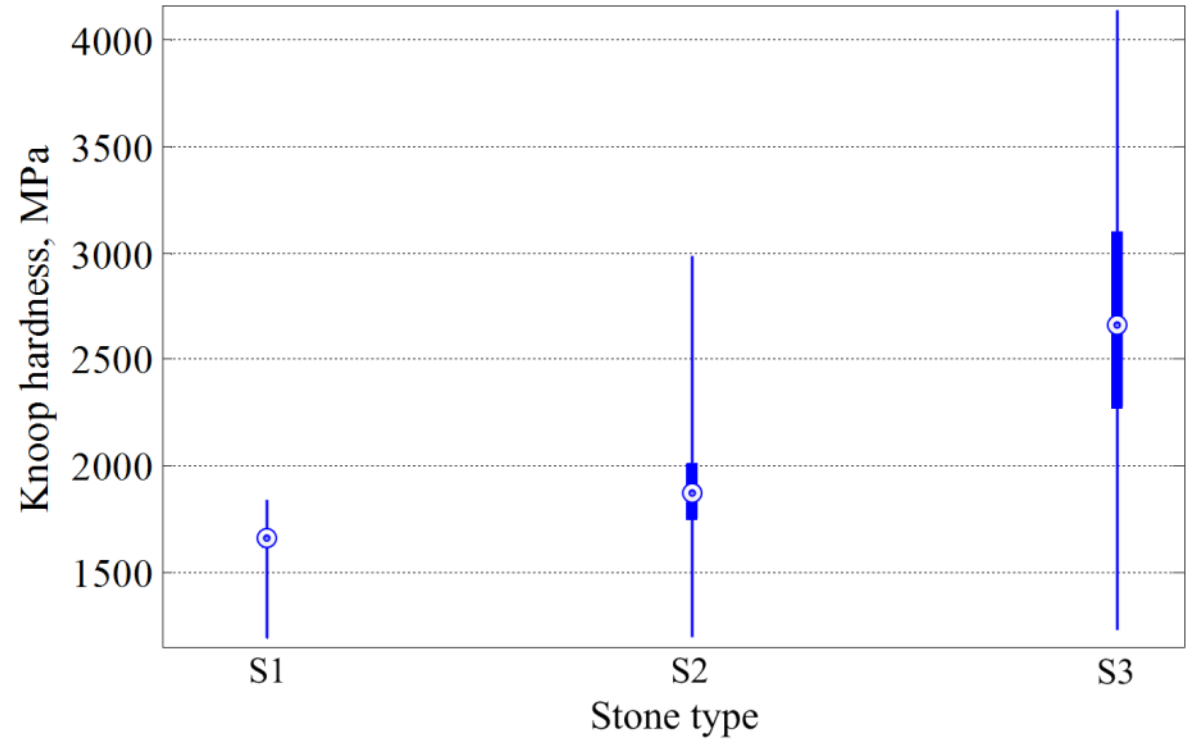

Fig. 3 Hardness measurements

\subsection{Experimental setup and drilling parameters}

Samples were drilled using a $5 \mathrm{~mm}$ twist drill bit with a $120^{\circ}$ point angle and cemented carbide inserts (Officina Martello di GIORGI F.LLI s.r.l., Italy). Drilling was performed on a custom-made triaxial milling machine retrofitted for the purpose of stone drilling investigation (Fig. 4).

The machine has been equipped with $0.4 \mathrm{~kW}$ permanent magnet synchronous motors (Model APM-SB04A, LS Mecapion, Korea), servomotor drives (Models DPCANIE030A400 and DPCANIE-060A400, Advanced Motion Control, USA), and ball screw assemblies (Model R16-5B1, Hiwin, Taiwan). It was controlled by a Linux-based, open architecture CNC system (EMC2 v2.3, 2009, from 2011 renamed to LinuxCNC and downloadable from linuxcnc.org). 


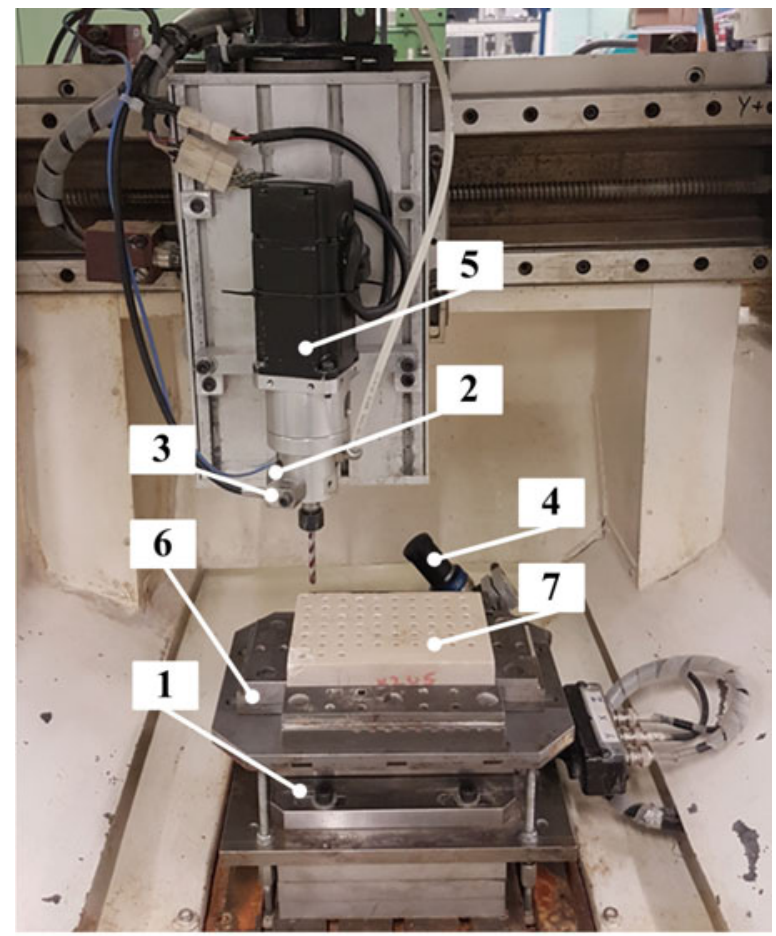

1. Force sensor

2. AE sensor

3. Accelerometer

4. Industrial camera with telecentric lens and illumination

5. Main spindle motor

6. Clamping device

7. Stone sample

Fig. 4 Experimental setup

Four types of process signals were measured during the drilling process. Apart from the control loop servomotor reference currents taken from the main spindle and feed drives, cutting forces were measured by using a triaxial Kistler piezoelectric dynamometer 9257B coupled with a charge amplifier 5017B, vibration signals were measured by using a triaxial Kistler piezoelectric accelerometer 8688A50 (measuring range of $0-5 \mathrm{kHz}$ ) coupled with an adequate signal conditioner 5134B, and acoustic emission (AE) signals were measured by using a Kistler piezoelectric industrial sensor 8152B1 (measuring range of 50-400 kHz) coupled with a 5125B interface module. Direct observations of drill bit cutting edges were performed by an industrial camera DMK41AF02 equipped with telecentric lenses TC2309.

Nine combinations of cutting parameters, i.e., cutting speeds $v_{\mathrm{c}}=[10,15,20] \mathrm{m} / \mathrm{min}$ and feed rates $f=[0.03,0.06,0.09] \mathrm{mm} / \mathrm{rev}$, were used in this study (Table 1 ). They were chosen based on tool manufacturer recommendations. Measurements performed with each combination of cutting parameters were randomly repeated seven times for each of four different wear levels: sharp drill bit $-\mathrm{SD}\left(V B_{\mathrm{MAX}}=[0,0.03] \mathrm{mm}\right)$, low worn drill bit $-\mathrm{LWD}$ $\left(V B_{\mathrm{MAX}}=[0.13,0.15] \mathrm{mm}\right)$, medium worn drill bit $-\operatorname{MWD}\left(V B_{\mathrm{MAX}}=[0.24,0.29] \mathrm{mm}\right)$, and worn drill bit $-\mathrm{WD}\left(V B_{\mathrm{MAX}}=[0.48,0.57] \mathrm{mm}\right)$. This means that for each combination of cutting parameters and stone sample 28 sets of process signals were measured. Overall, 756 sets of process signals were collected (28 sets per each of nine combinations of cutting parameters and three stone types). At the end, hardness features were extracted from all four types of process signals for each data set. 
Table 1 Cutting parameters

\begin{tabular}{|c|c|c|c|c|}
\hline \multirow{3}{*}{\multicolumn{2}{|c|}{$\begin{array}{l}\text { Cutting speed, } v_{\mathrm{c}} \\
\text { Rotational speed }\end{array}$}} & \multirow{2}{*}{\multicolumn{3}{|c|}{$\begin{array}{c}\text { Feed rate, } f \\
\mathrm{~mm} / \mathrm{rev}\end{array}$}} \\
\hline & & & & \\
\hline & & 0.03 & 0.06 & 0.09 \\
\hline $\mathrm{m} / \mathrm{min}$ & *rev/min & \multicolumn{3}{|c|}{$\mathrm{mm} / \mathrm{s}$} \\
\hline 10 & 637 & 0.31 & 0.64 & 0.95 \\
\hline 15 & 955 & 0.48 & 0.96 & 1.43 \\
\hline 20 & 1274 & 0.64 & 1.27 & 1.91 \\
\hline
\end{tabular}

\subsection{Data acquisition and signal processing}

Four types of servomotor current signals were measured: horizontal $\left(I_{\mathrm{X}}, I_{\mathrm{Y}}\right)$ and vertical $\left(I_{\mathrm{Z}}\right)$ feed drive currents, and main spindle current $\left(I_{\mathrm{MS}}\right)$. Whereas the horizontal feed drive currents $\left(I_{\mathrm{X}}, I_{\mathrm{Y}}\right)$ were low (usually below $\left.0.1 \mathrm{~A}\right)$, the hardness classification features were extracted from only $I_{\mathrm{Z}}$ and $I_{\mathrm{MS}}$ signals.

On the other hand, the main intention of measuring cutting forces was to compare performances of their features with those extracted from the current signals. Potential replacement of the force signals with the motor drive currents would simplify the design of the hardness monitoring system and significantly reduce its cost. Similarly to the feed drive currents, the force components $F_{\mathrm{X}}$ and $F_{\mathrm{Y}}$ were significantly smaller (approx. 10 times) than the vertical component $F_{\mathrm{Z}}$. Therefore, $I_{\mathrm{Z}}$ and $I_{\mathrm{MS}}$ were compared with $F_{\mathrm{Z}}$ and the resultant cutting force $F_{\mathrm{R}}$, respectively. The resultant force was determined based on all three force components $\left(F_{\mathrm{R}}=\sqrt{F_{\mathrm{X}}^{2}+F_{\mathrm{Y}}^{2}+F_{\mathrm{Z}}^{2}}\right)$.

Both types of signals were continuously sampled every $1 \mathrm{~ms}$. Maximum force/current values $\left(F_{Z_{-} \mathrm{MAX}}, F_{\mathrm{R} \_\mathrm{MAX}}, I_{Z_{-} \mathrm{MAX}}, I_{\mathrm{MS} \_\mathrm{MAX}}\right)$ were extracted from signals previously filtered with a Butterworth low-pass filter (cut-off frequency of $2 \mathrm{~Hz}$ ). In addition, the power of spectral components determined by using the Fast Fourier Transform (FFT) algorithm at the rotating frequency $\left(F_{Z_{-} \mathrm{RF}}, I_{\mathrm{MS} \_\mathrm{RF}}\right)$ and the tool frequency $\left(F_{\mathrm{Z}_{-} \mathrm{TF}}, I_{\mathrm{MS} \_\mathrm{TF}}\right)$ were also used as features needed for a hardness classification.

In order to analyse the applicability of vibration and AE signals, a set of features were extracted only from the frequency domain. Considering the vibration signals, measurements were performed in all three orthogonal directions ( $x$-, $y$-, and $z$-axis) and sampled using a 4 channel acquisition board (PCI-DAS4020/12, Measurement Computing, USA). All signals were measured with a sampling frequency of $100 \mathrm{kHz}$ for a period of two seconds after both cutting edges entered the material. The signals were transformed into the frequency domain by using the FFT algorithm. The power spectrum range of the transformed signals was constrained by the sensor operating range within an interval from $5 \mathrm{~Hz}$ to $5 \mathrm{kHz}$.

After the transformation, the power spectrum of each signal was divided into a series of samples, depending on the selected bandwidth. Altogether, 23 bandwidths $(5,10,20, \ldots, 100$, $200, \ldots, 1000,1500,2500$, and $5000 \mathrm{~Hz}$ ) were chosen and used in the analysis. For example, if the signal power spectrum was divided using a $1000 \mathrm{~Hz}$ bandwidth, we obtained five samples per signal, where each sample belonged to one of the following five frequency ranges: 5-1005, 1005-2005, 2005-3005, 3005-4005, 4005-5000 Hz. Since the upper frequency value of the last sample could not exceed $5 \mathrm{kHz}$, the bandwidth related to that sample was usually somewhat lower than the chosen one. The aforementioned predefined set of bandwidths was chosen in order to provide an analysis of vibration signals using different numbers of features per signal. In the case of the $5 \mathrm{~Hz}$ bandwidth, each signal was described 
by 999 features/samples, while in the case of the $5000 \mathrm{~Hz}$ bandwidth, only one feature per signal was extracted. The idea was to find the minimum number of features per signal which can adequately identify the stone hardness during drilling.

Once all samples of the analysed vibration signal related to the chosen bandwidth were determined, the energy $\left(\psi^{2}\right)$ of each sample was calculated using the expression

$$
\psi^{2}=\int_{f_{\mathrm{L}}}^{f_{\mathrm{U}}} S \mathrm{~d} f,
$$

where $S$ is the one-sided power spectrum density function of the analysed vibration signal and $f_{\mathrm{L}}$ and $f_{\mathrm{U}}$ are the lower and upper frequencies of the sample for which the energy is calculated [22]. The energies of the vibration signals were then used as stone hardness features. The features were analysed for each type of vibration signal individually $(X, Y, Z)$ and in combinations (XY, XZ, YZ, XYZ, XYZ $Z_{\text {SUM }}$ ). A detailed explanation of the methodology for feature extraction from vibration signals can be found in [23].

The last type of the analysed signal, i.e., the AE signal, was sampled at a frequency of 2 $\mathrm{MHz}$ using the same acquisition board as in the case of vibration signals. One sample with a duration of $0.1 \mathrm{~s}$ was taken per hole after both cutting edges entered the material. The signals were filtered using the Butterworth band-pass filter with a frequency bandwidth from $40 \mathrm{kHz}$ to $500 \mathrm{kHz}$. This was in accordance with the specified measurement range of the utilised sensor. Hardness features were extracted from the AE signals using the same methodology as in the case of the vibration signals, but with different frequency bandwidths of $5,10,15,20$, 30 and $40 \mathrm{kHz}$. The features were also analysed individually and in combinations.

\section{Results and discussion}

All features were processed by using a radial basis function neural network (RBF NN) algorithm. The utilised variant of the RBF NN algorithm is suitable for solving classification types of problems and is presented in [23]. From 756 sets of features, 432 sets were used in the RBF NN training phase, while the remaining 324 sets were used as test samples. Both, the training and the testing groups of data were built from features belonging to all tool wear levels, combinations of cutting parameters and stone types. The results are expressed as a classification success rate (CSR) factor, i.e., as the ratio of correctly classified samples to all tested samples belonging to each type of stone sample. The results achieved with features extracted from the forces and the currents signals are presented and compared in Table 2. It can be observed that both groups of features yielded very similar results (the CSR of the force features was in some situations up to $5 \%$ higher comparing to the CSR of the comparative features form the currents signals). The features from the time domain achieved a higher CSR than those extracted from the frequency domain. After combining all features of each type of signal separately, both types of signals achieved a relatively low CSR, which was around or below $65 \%$ (66.7\% vs $57.1 \%)$.

The most extensive analysis of features was conducted with vibration features due to the various number of combinations. The features (energies) were first analysed individually for each frequency bandwidth within the measurement range of $5 \mathrm{~Hz}-5 \mathrm{kHz}$. The features which satisfied the condition CSR $\geq 65 \%$ were combined and additionally analysed. This condition was determined based on the fact that no feature individually achieved a CSR equal or higher than $70 \%$. All features used in combinations were related to non-overlapping frequency ranges. In the case of energies extracted from two or more overlapping ranges, the one with the highest CSR value was taken for further analysis [23]. The best results of each combination are presented in Table 3. 
Table 2 Classification results achieved with features extracted from forces and current signals

\begin{tabular}{|c|c|c|c|c|c|c|c|c|c|}
\hline \multirow{2}{*}{$\begin{array}{c}\text { Force } \\
\text { features }\end{array}$} & \multicolumn{4}{|c|}{ Classification success rate, $\%$} & \multirow{2}{*}{$\begin{array}{l}\text { Current } \\
\text { features }\end{array}$} & \multicolumn{4}{|c|}{ Classification success rate, $\%$} \\
\hline & $\mathrm{S} 1$ & $\mathrm{~S} 2$ & S3 & Avg. & & S1 & $\mathrm{S} 2$ & S3 & Avg. \\
\hline$F_{\mathrm{Z} \_ \text {MAX }}$ & 52.8 & 56.5 & 50 & 53.1 & $I_{\mathrm{Z} \_\mathrm{MAX}}$ & 45.4 & 51.9 & 55.6 & 50.9 \\
\hline$F_{\mathrm{R} \_ \text {MAX }}$ & 51.9 & 53.7 & 49.1 & 51.5 & $I_{\mathrm{MS} \_\mathrm{MAX}}$ & 48.2 & 50.9 & 45.4 & 48.2 \\
\hline$F_{\mathrm{Z} \_\mathrm{MAX}}+F_{\mathrm{R} \_\mathrm{MAX}}$ & 51.9 & 58.3 & 50 & 53.4 & $I_{\mathrm{Z} \_\mathrm{MAX}}+I_{\mathrm{MS} \_\mathrm{MAX}}$ & 49.1 & 56.5 & 59.3 & 54.9 \\
\hline$F_{\mathrm{Z} \_\mathrm{RF}}$ & 39.8 & 36.1 & 28.7 & 34.9 & $I_{\mathrm{MS} \_\mathrm{RF}}$ & 28.7 & 37.1 & 52.8 & 39.5 \\
\hline$F_{\mathrm{Z} \_\mathrm{TF}}$ & 39.8 & 27.8 & 58.3 & 41.9 & $I_{\mathrm{MS} \_\mathrm{TF}}$ & 26.9 & 39.8 & 50 & 38.9 \\
\hline$F_{\mathrm{Z} \_\mathrm{RF}}+F_{\mathrm{Z} \_\mathrm{TF}}$ & 61.1 & 46.3 & 62.9 & 56.8 & $I_{\mathrm{MS} \_\mathrm{RF}}+I_{\mathrm{MS} \_\mathrm{TF}}$ & 49.1 & 45.4 & 64.8 & 53.1 \\
\hline $\begin{array}{c}F_{\mathrm{Z} \_\mathrm{MAX}}+F_{\mathrm{R} \_\mathrm{MAX}} \\
+F_{\mathrm{Z} \_\mathrm{RF}}+F_{\mathrm{Z} \_\mathrm{TF}}\end{array}$ & 75.9 & 63.9 & 60.2 & 66.7 & $\begin{array}{l}I_{\mathrm{Z} \_\mathrm{MAX}}+I_{\mathrm{MS} \_\mathrm{MAX}} \\
+I_{\mathrm{MS} \_\mathrm{RF}}+I_{\mathrm{MS} \_\mathrm{TF}}\end{array}$ & 59.3 & 59.3 & 52.8 & 57.1 \\
\hline
\end{tabular}

Table 3 Classification results of different combinations of features extracted from vibration signals which individually satisfied CSR $>65 \%$

\begin{tabular}{|c|c|c|c|c|}
\hline \multirow{2}{*}{$\begin{array}{c}\text { Feature } \\
\text { combination }\end{array}$} & \multicolumn{4}{|c|}{ Classification success rate, \% } \\
\cline { 2 - 5 } & $\mathrm{S} 1$ & $\mathrm{~S} 2$ & $\mathrm{~S} 3$ & Avg. \\
\hline $\mathrm{XY}$ & 71.3 & 75 & 77.8 & 74.7 \\
\hline $\mathrm{YZ}$ & 75.9 & 79.6 & 90.7 & 82.1 \\
\hline $\mathrm{XZ}$ & 66.7 & 70.4 & 95.7 & 77.7 \\
\hline $\mathrm{XYZ}$ & 80.6 & 75 & 95.7 & 83.6 \\
\hline $\mathrm{XYZ}+\mathrm{XYZ}$ & 88.9 & 78.7 & 99.1 & 88.9 \\
\hline
\end{tabular}

$\mathrm{XY}$ - Combination of energies of different frequency ranges measured in $x$ - and $y$-axis direction

$Y Z$ - Combination of energies of different frequency ranges measured in $y$ - and $z$-axis direction

$\mathrm{XZ}$ - Combination of energies of different frequency ranges measured in $x$ - and $z$-axis direction

$X Y Z$ - Combination of energies of different frequency ranges measured in $x$-, $y$ - and $z$-axis direction

$\mathrm{XYZ}_{\mathrm{SUM}}$ - Sum of energies of different frequency ranges measured in $x$-, $y$-, and $z$-axis direction

The features extracted from the vibration signals showed a significantly higher precision in the stone hardness classification than the cutting forces and the servomotor currents. The best average CSR factor was near $90 \%$. These results indicate that vibration signals are capable of classifying stone hardness with a similar success regardless of the tool wear level. This can be observed from Table 4, where the CSR factors achieved with the best combination of vibration features $\left(\mathrm{XYZ}+\mathrm{XYZ} \mathrm{Z}_{\mathrm{SUM}}\right)$ are presented for every tool wear level separately.

Table 4 Stone hardness classification results achieved with vibration feature combination $\mathrm{XYZ}+\mathrm{XYZ} \mathrm{Z}_{\mathrm{SUM}}$

\begin{tabular}{|c|c|c|c|c|c|}
\hline \multirow{2}{*}{ Stone type } & \multicolumn{5}{|c|}{ Classification success rate, \% } \\
\cline { 2 - 5 } & \multicolumn{4}{|c|}{ Tool wear level } \\
\cline { 2 - 5 } & SD & LWD & MWD & WD & \\
\hline S1 & 88.9 & 100 & 92.6 & 74.1 & 88.9 \\
\hline S2 & 70.4 & 70.4 & 77.8 & 96.3 & 78.7 \\
\hline S3 & 100 & 100 & 100 & 96.3 & 99.1 \\
\hline
\end{tabular}

The average CSR values of the best combination of the vibration features (XYZ + $\left.\mathrm{XYZ}_{\mathrm{SUM}}\right)$ show that this combination can accomplish the highest classification precision for the stone sample S3 (CSR $=99.1 \%)$, which was characterised by the highest median hardness value. The lowest classification result was accomplished for the stone sample S2 
$(\mathrm{CSR}=78.7 \%)$, whose median hardness value was lower than in the case of S3 and slightly higher than in the case of S1. This result can be explained by the fact that all stone samples were very heterogeneous, and hardness values of stone samples S1 and S2 showed overlapping characteristics in some measurements. Hence, their median hardness values were not so distinctive.

The $\mathrm{AE}$ features (energies) were extracted from raw $\mathrm{AE}$ signals using the abovementioned $5,10,15,20,30$ and $40 \mathrm{kHz}$ frequency ranges. They were also analysed individually and in combinations. The CSR values were noticeably lower than those achieved using the vibration features. The highest individually achieved CSR was $41.9 \%$, and it belonged to the energy extracted from the $120-125 \mathrm{kHz}$ frequency interval ( $5 \mathrm{kHz}$ range). Therefore, all features which satisfied the CSR $\geq 40 \%$ condition were mutually combined in the second stage of the analysis and the results are shown in Table 5.

Table 5 Classification results achieved with the AE feature combination (each feature individually satisfied CSR $\geq 40 \%$ condition)

\begin{tabular}{|c|c|c|c|}
\hline \multicolumn{4}{|c|}{ Classification success rate, \% } \\
\hline S1 & S2 & S3 & Avg. \\
\hline 50.9 & 51.6 & 38.9 & 47.2 \\
\hline
\end{tabular}

At the end, the best features of the servomotor currents, vibrations and AE were mutually combined and the results are presented in Table 6 . The results indicate that the combinations of features extracted from different types of process signals could not improve the classification precision achieved with the best combination of features extracted only from the vibration signals.

Table 6 Classification results of combinations of the best feature combinations belonging to each type of signal (servomotor currents, vibrations and AE) individually

\begin{tabular}{|c|c|c|c|c|}
\hline \multirow{2}{*}{ Feature combination } & \multicolumn{4}{|c|}{ Classification success rate, $\%$} \\
\hline & $\mathrm{S} 1$ & $\mathrm{~S} 2$ & $\mathrm{~S} 3$ & Avg. \\
\hline$\left(X Y Z+X Y Z_{S U M}\right)+I$ & 79.6 & 80.6 & 79.6 & 79.9 \\
\hline$\left(X Y Z+X Y Z_{S U M}\right)+A E$ & 88.9 & 72.2 & 94.4 & 85.2 \\
\hline$\left(X Y Z+X Y Z_{S U M}\right)+A E+I$ & 86.1 & 71.3 & 75 & 77.5 \\
\hline
\end{tabular}

$\mathrm{I}-\left(I_{\mathrm{Z} \_\mathrm{MAX}}+I_{\mathrm{MS} \_\mathrm{MAX}}+I_{\mathrm{MS} \_ \text {RF }}+I_{\mathrm{MS} \_\mathrm{TF}}\right)$

\section{Conclusions}

In this experimental study an application of four types of signals in the stone hardness classification during the drilling process has been analysed. Features were extracted from cutting forces, servomotor currents, vibration and acoustic emission signals for all combinations of the analysed cutting parameters, drill bit wear levels and stone types. The idea was to analyse the possibility of using the chosen types of process signals in the stone hardness monitoring without using the information about the drill bit wear level. Since drill bit wear cannot be measured in on-line hardness classification, but can only be estimated, this estimation would inevitably introduce an additional error in the hardness classification process.

The obtained results indicate the efficacy and potential industrial applicability of features extracted from vibration signals in the indirect on-line monitoring of stone hardness during machining operations. The features extracted from vibration signals achieved a high classification precision, practically regardless of the intensity of the drill bit wear. 
Furthermore, the integration of adequate vibration sensors in the machine tools structure is relatively simple and cost effective.

The features extracted from other types of process signals accomplished a lower hardness classification precision when analysed individually for each type of signal or in combinations. This means that the features extracted from force signals, servomotor currents and acoustic emission were not able to adequately classify stone hardness and/or did not have the capacity to isolate the influence of the tool wear rate on the overall hardness classification process. Although force and current signals will not be used in our future research, additional analyses will be performed with vibration signals higher than $5 \mathrm{kHz}$ (up to $10 \mathrm{kHz}$ ) as well as acoustic emission signals higher than $400 \mathrm{kHz}$ (up to $900 \mathrm{kHz}$ ).

Finally, it can be also concluded that the results obtained in this study can be particularly interesting from the aspect of the adaptive process control system implementation. Machine tools used in stone machining which can adjust cutting speed and feed rate during the machining process already exist on the market, but mostly without a possibility of automatic parameters adjustment due to the absence of quality process monitoring systems.

\section{REFERENCES}

[1] Hoseinie SH, Ataei M, Mikaiel, R (2012) Comparison of Some Rock Hardness Scales Applied in Drillability Studies. Arab J Sci Eng 37:1451-1458. https://doi.org/10.1007/s13369-012-0247-9

[2] Bamford WE, Duyse vH, Nieble C, Rummel F, Broch E, Franklin JA, et al (1978) Suggested methods for determining hardness and abrasiveness of rocks. Int J Rock Mech Min Sci Geomech Abstr 15:89-97.

[3] Shalabi FI, Cording EJ, Al-Hattamleh OH (2007) Estimation of rock engineering properties using hardness tests. Eng Geol 90:138-147. https://doi.org/10.1016/j.enggeo.2006.12.006

[4] Aydin A, Basu A (2005) The Schmidt hammer in rock material characterization. Eng Geol 81: 1-14. https://doi.org/10.1016/j.enggeo.2005.06.006

[5] Yaşar E, Erdoğan Y (2004) Estimation of rock physicomechanical properties using hardness methods. Eng Geol 71: 281-288. https://doi.org/10.1016/S0013-7952(03)00141-8

[6] Aoki H, Matsukura Y (2007) A new technique for non-destructive field measurement of rock-surface strength: an application of the Equotip hardness tester to weathering studies. Earth Surf Proc Land 32:1759-1769. https://doi.org/10.1002/esp.1492

[7] Theodoridou M, Dagrain F, Ioannou I (2012) Correlation of stone properties using standardized methodologies and non-standardized micro-destructive techniques. Proceedings of the 12th International Congress on the Deterioration and Conservation of Stone, New York, USA. https://www.researchgate.net/publication/269696824. Accessed 5 June 2019

[8] Bilim N (2011) Determination of drillability of some natural stones and their association with rock properties. Sci Res Essays 6:382-387. https://doi.org/10.5897/SRE10.878

[9] Stavropoulou MC, Giannakopoulos KF, Exadaktylos GE (2004) Experimental and numerical study of mechanical cutting of dionysos marble. Proceedings of the 7th National Congress on Mechanics, Chania, 2004.

[10] Valentini E, Benincasa A, Tiano P, Rescic S (2019) On site drilling resistance profiles of natural stones. https://www.drms-cordless.com/wp-content/uploads/2018/10/604-On-Site-Drilling.pdf. Accessed 5 June 2019

[11] Pamplona M, Kocher M, Snethlage R, Aires-Barros L (2007) Drilling resistance: Overview and perspectives. Z Dtsch Ges Geowiss 158: 665-679. https://doi.org/10.1127/1860-1804/2007/ 0158-0665

[12] Al-Naddaf MM, Wakid F, Abu Alhassan Y (2013) Micro-drilling resistance measurement: a new technique to estimate the porosity of a building stone. Mediterr Archaeol Ar 13:227-235.

[13] Yurdakul M, Akdas H (2015) The effect of rock mineralogic and petrographic properties on stone cutting feed rate. Proceedings of the 49th US Rock Mechanics / Geomechanics Symposium, San Francisco, USA.

[14] Hamade RF, Pusavec F, Manthri SP, Dillon OW, Jawahir IS (2012) A methodology for the optimization of PCD compact core drilling in basalt rock, Int J Adv Manuf Tech 61:1/4 369-377. https://doi.org/10.1007/s00170-011-3696-5. 
[15] Hamade RF, Manthri SP, Pusavec F, Zacny KA, Taylor LA, Dillon OW, Rouch K, Jawahir IS (2010) Compact core drilling in basalt rock using rectangular PCD tool inserts: wear characteristics and cutting forces, J Mater Process Tech 210:10 1326-1339. https://doi.org/10.1016/j.jmatprotec.2010.03.023

[16] Turchetta S (2009) Cutting force on a diamond grit in stone machining, Int J Adv Manuf Tech 44:854861. https://doi.org/10.1007/s00170-008-1905-7

[17] Turchetta S (2012) Cutting force and diamond tool wear in stone machining, Int J Adv Manuf Tech 61:441-448. https://doi.org/10.1007/s00170-011-3717-4

[18] Jantunen E (2002) A summary of methods applied to tool condition monitoring in drilling. Int J Mach Tool Manu 42:997-1010. https://doi.org/10.1016/S0890-6955(02)00040-8

[19] Teti R, Jemielniak K, O’Donnell G, Dornfeld D (2010) Advanced monitoring of machining operations. CIRP Ann-Manuf Tech 59:717-739. https://doi.org/10.1016/j.cirp.2010.05.010

[20] Zhang K-F, Yuan H-Q, Nie P (2015) A method for tool condition monitoring based on sensor fusion. J Intell Manuf 26:1011-1026. https://doi.org/10.1007/s10845-015-1112-y

[21] Siddhpura A, Paurobally R (2013) A review of flank wear prediction methods for tool condition monitoring in a turning process. Int J Adv Manuf Tech 65:371-393. https://doi.org/10.1007/ s00170-0124177-1

[22] Scheffer C, Heyns PS, Klocke F (2003) Development of a tool wear-monitoring system for hard turning. Int J Mach Tool Manu 43:973-985. https://doi.org/10.1016/S0890-6955(03)00110-X

[23] Klaic M, Murat Z, Staroveski T, Brezak D (2018) Tool wear monitoring in rock drilling applications using vibration signals. Wear 408-409:222-227. https://doi.org/10.1016/ j.wear.2018.05.012.

Submitted: $\quad 28.11 .2019$

Accepted: $\quad 19.12 .2019$
Miho Klaic, $\mathrm{PhD}$

Assist. Prof. Tomislav Staroveski Zrinka Murat

Department of Technology, Faculty of Mechanical Engineering and Naval Architecture, University of Zagreb, Croatia

Assoc. Prof. Danko Brezak

Department of Robotics and Production Systems Automation, Faculty of Mechanical Engineering and Naval Architecture, University of Zagreb, Croatia

Corresponding author e-mail address: danko.brezak@fsb.hr 